\title{
Current issues in mode choice modeling
}

\author{
Maya Abou-Zeid • Darren M. Scott
}

Published online: 24 April 2011

(C) Springer Science+Business Media, LLC. 2011

We are pleased to present the 2011 Transportation Research Board (TRB) special issue of Transportation comprising seven papers that were presented at the 90th Annual Meeting of the organization. These special issues, published annually by Transportation since 2005 , represent a partnership between Transportation and two standing committees of the TRB to highlight state-of-the-art research in travel behavior modeling and forecasting. The committees involved in this partnership are the Committee on Traveler Behavior and Values (ADB10) and the Committee on Transportation Demand Forecasting (ADB40).

The theme of this special issue is current issues in mode choice modeling. Mode choice has an especially important place in travel behavior analysis because of the important role of public transportation in transportation policy making (Ortúzar and Willumsen 2011). Mode choice models constituted most of the early applications of discrete choice models in the 1960s and 1970s (Ben-Akiva and Lerman 1985) and continue to be actively pursued by transportation researchers.

A number of recent developments in both theory and data have supported the development of behaviorally richer mode choice models. First, regarding theory, advanced models such as the logit mixture model (McFadden and Train 2000) are being increasingly applied to mode choice models to model, for instance, distributed values of time; another example is the Multiple Discrete-Continuous Extreme Value (MDCEV) model (Bhat 2008) which has been used to develop joint models of travel mode and other travel dimensions. Frameworks such as the Hybrid Choice model (Ben-Akiva et al. 2002; Walker and Ben-Akiva 2002) have allowed researchers to model the influence of latent factors on mode choice behavior, such as perceptions and attitudes that affect the desirability of a certain mode as well as awareness of and familiarity with certain modes that influence the

\footnotetext{
M. Abou-Zeid

Department of Civil and Environmental Engineering, American University of Beirut, P.O. Box 11-0236, FEA-CEE, Riad El- Solh, Beirut 1107 2020, Lebanon e-mail:ma202@aub.edu.lb

D. M. Scott $(\bowtie)$

TransLAB (Transportation Research Lab), School of Geography and Earth Sciences, McMaster University, Hamilton, ON L8S 4K1, Canada e-mail: scottdm@mcmaster.ca
} 
choice set formation. Second, with respect to data, we have witnessed numerous developments in stated preferences survey techniques (Louviere et al. 2000) that have been increasingly applied to mode choice experiments. Techniques that combine revealed (RP) and stated preferences (SP) data have been developed and applied in mode choice modeling contexts. Furthermore, the availability of GPS data has enabled the measurement of some variables that are important in models of mode choice, such as travel time reliability.

This special issue contains seven papers that highlight important current issues in mode choice modeling. Two papers address choice set considerations, in particular whether carpooling and transit are considered in the choice set. One of these two papers also considers the impacts of some qualitative transit service attributes on mode choice. Four papers explore factors hypothesized to influence mode choice: travel time unreliability, attitudes, the built environment, and inertia. Finally, one paper develops a system of hierarchical rule-based models for estimating several household-level travel attributes including number of trips by mode. A summary of these papers follows.

Two papers in this special issue, Habib et al. and Outwater et al., address choice set considerations in mode choice modeling. Habib et al. address the consideration of carpooling in the mode choice set for commuting to work. Their hypothesis is that even if people have a car to share, it is their willingness to carpool that makes carpooling a feasible option to them. They develop a hybrid discrete choice model that combines a mode choice model with a carpool consideration model, including a number of stated indicators related to the carpooling decision. Estimating the model using a commuter sample from Edmonton, Alberta, one of their main findings is that certain variables, such as travel demand management policies like flexible work hours, may affect differently the consideration of carpooling in the choice set, and the choice of carpooling once it is considered in the choice set, and these different effects need to be carefully considered in the evaluation of policies.

Reporting on the first phase of TCRP Project H-37, Outwater et al. study the extent to which people are aware of and familiar with transit services available to them. Their finding of substantial levels of unawareness of these services, based on a sample of transit and non-transit users in Salt Lake City, Utah, calls for the extension of mode choice models currently used in practice which assume perfect awareness, by conditioning them on choice set models. Another important direction in this paper is the quantification of non-traditional attributes of premium transit services, such as reliability, availability of real-time transit information, modern stop design, and the presence of modern on-board amenities. Such attributes are not typically included in standard mode choice models, and their effects are usually captured by the mode specific constants. By incorporating these attributes in a mode choice model also developed for Salt Lake City, the authors estimate the combined effect of all these premium service attributes as an advantage of over 26 min of equivalent in-vehicle time for a 30-min transit trip with a 10 -min wait.

A number of studies have recognized the influence of travel time unreliability on travel decisions, especially mode choice and time of travel. Sweet and Chen address this problem from a new perspective: rather than looking at corridor specific unreliability, they devise a measure of spatial travel-time unreliability that captures unreliability at the level of an entire network or for specific zones, by factoring in trips conducted over multiple origins and destinations. The availability of a GPS survey collected in Chicago allows them to measure the spatial variation in unreliability of travel by auto, which they find to be significant over different time periods. They then incorporate this measure of unreliability in a model of mode choice of auto or transit applied to a travel diary data set collected in Chicago. The influence of unreliability on mode switching from car to train turns out to be 
strongest in areas where the train is competitive with the car in terms of travel time, but the overall effect of unreliability on mode switching is modest.

The transportation community has long recognized the importance of attitudes and the built environment in influencing mode choice decisions. Popuri et al. examine the former in the context of the choice of car or public transit for commuting in the Chicago area. Using factor analysis and a logit model, they find six important attitudes influencing these decisions: general attitude towards public transportation, need for reliable and stress-free commute, and tolerance to walking and waiting increase the likelihood of using transit, while need for privacy and comfort, dynamism and complexity of the work schedule, and perceived safety of travel decrease the likelihood of using transit. Their model gives more intuitive estimates of the elasticity of transit demand with respect to level of service variables. The main policy implications are that transit ridership can be increased by marketing campaigns that stress the reliable, stress-free, and productive attributes of a transit commute as well as those that subsidize riders who convince their friends to try transit.

Tracy et al. examine the relationship between mode choice and the built environment using Buffalo, New York for their case study. However, rather than modeling the mode choice decisions of individuals, they instead choose to model mode choice proportions (i.e., non-motorized, transit, vehicle) for traffic analysis zones (TAZs) using stepwise linear regression. They derive over 50 explanatory built environment variables corresponding to the 3Ds: density, diversity, and design. In the end, however, they select only 17 for inclusion in the linear models. Their results are unequivocal and encouraging: the built environment is highly correlated to mode choice at the aggregate level of TAZs, even after controlling for zonal demographics. Furthermore, their results suggest that characteristics of the built environment impact specific modes differently. This finding is particularly useful to proponents of smart growth planning in the sense that it is possible to identify the most important aspects of the built environment for encouraging non-motorized travel and transit usage.

Cherchi and Manca investigate the role of inertia in mode choice decisions. While the topic of inertia has received some attention in the broader travel behavior literature, few studies have addressed it in the context of mode choice presumably due to data limitations - the study of inertia has typically relied on panel data. However, Cherchi and Manca demonstrate how a mixed RP/SP data set can be used to account for inertia, effectively overcoming this issue. In their study, they also test and compare many measures designed to capture inertia, both those used in past studies and new ones that they propose. They undertake an exhaustive analysis of inertia using a data set collected in 1998 pertaining to a traveler's choice between car, bus, and train for suburban trips in and out of Cagliari, the capital of Sardinia, Italy. They present results for 12 mixed logit models, seven of which include one inertia effect and five of which include two inertia effects_- one pertaining to RP observations and the other to SP situations. Their findings not only provide convincing evidence as to why inertia should be accounted for in mode choice models, they also offer practical guidance in terms of model specification to estimate inertia correctly. Although Cherchi and Manca's study is conceived within the context of mode choice, its methodological contributions concerning inertia can inform other areas of travel behavior research and thus will be of interest to the broader transportation community.

Rashidi and Mohammadian's work concludes this special issue. Unlike the six preceding studies which offer substantive insights to further our understanding of mode choice decisions, Rashidi and Mohammadian's work has a practical orientation-that is, they present results from a modeling exercise designed to estimate several household-level 
travel attributes: total number of daily trips, number of trips by purpose, number of trips by mode, and daily average commute distance. They apply a data mining algorithm known as the Exhaustive CHAID (Chi-squared Automatic Interaction Detector) to data obtained from the 2001 National Household Travel Survey (NHTS) of the United States. With respect to mode choice, they present decision trees for auto trips and non-motorized trips. Like Tracy et al.'s study, built environment variables are found to play an important role in mode choice. Rashidi and Mohammadian validate their system of hierarchical rule-based models using data from Des Moines, Iowa (an add-on to the NHTS).

Collectively, the papers included in this special issue advance our understanding of mode choice modeling in terms of choice set considerations and factors hypothesized to influence mode choice decisions-namely, travel time unreliability, attitudes, the built environment, and inertia. However, we live in a dynamic, inter-connected world. Global events, such as unrest in the Middle East, and global concerns, such as climate change, are catalysts that can affect mobility tool ownership (e.g., cars, transit passes) and mode choice decisions in unknown and profound ways. As the price of oil continues to climb and as public awareness of climate change continues to grow, will people choose more sustainable modes of transport such as walking, cycling, or transit? Will the composition of the automobile fleet change as affordable electric and hybrid vehicle options are made available to the public? Will more employers offer telework programs? Answers to questions such as these are left to future research. Such questions, although simple, do suggest that our understanding of factors governing mode choice today will necessarily have to be revisited in the future.

To conclude, we wish to acknowledge the efforts of Kimberly Fisher, the TRB staff representative to the standing committees responsible for this special issue; Eric Miller, Chair of the Committee on Traveler Behavior and Values (ADB10); Tom Rossi, Chair of the Committee on Transportation Demand Forecasting (ADB40); and Martin Richards, the Editor-in-Chief of Transportation, for making this special issue possible. We would also like to thank the authors and anonymous reviewers.

\section{References}

Ben-Akiva, M., Lerman, S.: Discrete choice analysis: theory and application to travel demand. MIT Press, Cambridge (1985)

Ben-Akiva, M., McFadden, D., Train, K., Walker, J., Bhat, C., Bierlaire, M., Bolduc, D., Boersch-Supan, A., Brownstone, D., Bunch, D.S., Daly, A., de Palma, A., Gopinath, D., Karlstrom, A., Munizaga, M.A.: Hybrid choice models: progress and challenges. Mark Lett 13, 163-175 (2002)

Bhat, C.: The multiple discrete-continuous extreme value (MDCEV) model: role of utility function parameters, identification considerations, and model extensions. Trans Res B 42, 274-303 (2008)

Louviere, J.J., Hensher, D.A., Swait, J.D.: Stated choice methods: analysis and applications. Cambridge University Press, Cambridge (2000)

McFadden, D., Train, K.: Mixed MNL models for discrete response. J Appl Econ 15, 447-470 (2000)

Ortúzar, J.D., Willumsen, L.G.: Modelling Transport, 4th edn. Wiley, Chichester (2011)

Walker, J., Ben-Akiva, M.: Generalized random utility model. Math Soc Sci 43, 303-343 (2002)

\section{Author Biographies}

Maya Abou-Zeid is an assistant professor of Civil and Environmental Engineering at the American University of Beirut and a research affiliate of the Intelligent Transportation Systems program at the Massachusetts Institute of Technology. Her research interests include travel demand forecasting, market research, and urban transportation planning. 
Darren M. Scott is an Associate Professor of Geography at McMaster University. A transportation geographer by training, Dr. Scott's fields of expertise include activity-travel behavior modeling and analysis, sustainable transportation (congestion, emissions, and aging populations), time geography, geographic information science, critical transportation infrastructure, and integrated land-use and transportation models. 